\section{Growing old(er) with postinfectious bronchiolitis obliterans}

\author{
Paul Cullinan, ${ }^{1}$ Andrew Bush ${ }^{2}$
}

Most healthy children shrug off viral respiratory tract infections with little difficulty or assistance and a full recovery is the norm. A small minority, in contrast, are left with serious consequences. Important among these is postinfectious bronchiolitis obliterans (pBO) characterised by persistent-and sometimes severe-airway obstruction with functional and radiological evidence of small airway involvement that is generally unresponsive to bronchodilator or steroid treatment. Diagnosis is usually confirmed by high resolution computed tomography scanning although the images can be confused with asthma ${ }^{1}$ and clinical context is everything. Lung biopsy is rarely needed, but if it is done, fibrosis and obliteration of the distal airways are the cardinal features. Treatment options are limited and proof of their effectiveness largely anecdotal; there are no relevant randomised controlled trials but asthma therapies, including bronchodilators, and long term azithromycin are often used. Supportive care should be offered, with oxygen as needed, avoidance of indoor and outdoor pollution, especially tobacco smoke, immunisations including pneumococcal and influenza, and good nutrition.

In most settings, $\mathrm{pBO}$ is undoubtedly rare but in the absence of systematic case registration its incidence is unmeasured. While cases have been reported in many different countries, there has been, for around 30 years, a striking preponderance from the southern 'cone' of South America (Chile, Argentina and southern Brazil) where the condition seems to have been more common than elsewhere. For example, $28 \%$ of 415 children admitted with an acute lower respiratory infection over a 17-year period to a hospital in Buenos Aires developed pBO (a further $15 \%$ died) over an unquantified period of observation. $^{2}$ In 1998, 45 children were

\footnotetext{
${ }^{1}$ Department of Occupational and Environmental Medicine, National Heart and Lung Institute, Imperial College, London, UK; ${ }^{2}$ Department of Paediatric Respiratory Medicine, Royal Brompton Hospital and Imperial College, London, UK

Correspondence to Dr Paul Cullinan, Department of Occupational and Environmental Medicine, National Heart and Lung Institute, Imperial College, London SW3 6LR, UK; p.cullinan@imperial.ac.uk
}

admitted to a hospital in Santiago, Chile, with viral pneumonia during an adenovirus epidemic; 5 years later, among the 38 survivors there were 18 (47\%) with evidence of pBO. ${ }^{3}$ Why these figures should be apparently so much higher than elsewhere is unclear; the severity of much pBO makes any ascertainment bias improbable. A more likely explanation lies in the regional and temporal distributions of respiratory viruses and their transmission. There is evidence for a remarkably strong association between pBO in Argentinean children and adenovirus infection ${ }^{4}$ and reasonable evidence that some serotypes (Ad3, Ad7 and Ad11) are particularly implicated. ${ }^{5} 6$ The risk of $\mathrm{pBO}$ is much higher in children with a severe initial illness as indicated, for example, by a requirement for intensive care or mechanical ventilation but there is far less convincing evidence for an independent effect of poverty or environmental smoke exposure although these may, of course, increase the risk of adenovirus infection in the first place. Intriguingly, there is anecdotal evidence that the incidence of $\mathrm{pBO}$ has diminished in southern South America, coincident with a decline in reported Ad7 variants in regional virus surveillance programmes since 1995 , and an apparent absence since $2005 .^{7}$ However, it would be a mistake to think the disease is disappearing altogether.

An earlier editorial in this journal commented that 'we do not yet know what the impact of this condition will be on respiratory reserve and decay in lung function in adult life'. ${ }^{8}$ Thirty-five years later, Thorax offers an insight. ${ }^{9}$ Forty-six children with pBO diagnosed in urban Argentina have been followed with repeated measurements of spirometry for an average of 12 years; whether their experience is representative is unclear since they were selected from a total cohort of 155. At a mean age of 9 years they, on average, had severe airway obstruction with functional evidence of gas trapping that was reportedly unresponsive to bronchodilator treatment. In the ensuing years, when spirometry was expressed as z-scores (the only way that allows us to make sense of developmental changes), there was a decline over time. More limited data on hyperinflation suggested this too declined, and in most children hypoxaemia resolved. There were no data on carbon monoxide transfer or any other surrogate for alveolar-capillary membrane size. Although we are provided with little detail, 'few' subjects were reported by the end of follow-up to have a significant response to treatment with inhaled salbutamol. Readmissions for respiratory disease became less common as the children grew older but it is clear that a significant proportion of children with BO following an early viral infection fail to develop adequate respiratory reserve and many are left with serious, incurable comorbidities. Three-quarters of the cohort had bronchiectasis on CT (emphasising that despite the name, $\mathrm{pBO}$ is often a proximal as well as distal airway disease), six of whom required lobectomy or pneumonectomy; none however needed supplemental oxygen after the age of 10 years. Notably, nine children developed major chest deformities with three undergoing corrective surgery. These are important data for clinicians discussing $\mathrm{pBO}$ in the UK, although the usual caveats about extrapolating between very disparate environments apply.

How should we interpret the lung function findings in light of current knowledge about lung development? The decline in z-score spirometry over time implies either an ongoing active process in the airways or that the initial hit caused not merely severe airway obstruction, but also impaired the subsequent ability of the airways to grow. Given the almost total resistance to therapy of $\mathrm{pBO}$, the latter is more likely, and contrasts markedly with the airflow obstruction of severe asthma, which tracks into late middle age without any accelerated decline. ${ }^{10} 11$ However, the recovery from hypoxaemia may imply that there is some alveolar regeneration; indeed, recent histological data in monkeys ${ }^{12}$ and hyperpolarised helium work in humans ${ }^{13} 14$ imply that neoalveolarisation may extend throughout the period of somatic growth, longer than previously thought.

The difficulty for the clinician is that reports of average experiences such as these tend to obscure the obvious differences in individual outcomes. Clearly, some children with pBO are left with devastating structural and functional lung disease while for others the effects are more subtle. While most do not have airway obstruction that is sensitive to bronchodilation, this is not always the case and an individually tailored approach to management is essential-not only during paediatric care but, as this series demonstrates, on transfer to adult services. $\mathrm{pBO}$ is, thankfully, not common but 
there are analogies with other damaging, early-life events (notably bronchopulmonary dysplasia associated with preterm birth) that are more common and that increasingly will deliver into the hands of adult respiratory physicians young adults whose lungs are irreparably impaired. Careful, planned and sensitive arrangements for transition from paediatric to adult services are essential for these adolescents and should include a management plan that, as for other lifelong respiratory diseases of childhood, extends well into the future and provides informed advice and support on employment options and the other rituals of adulthood. In the UK, there is an invaluable patient support group (http://www.breathtakers.org.uk/) with useful information also for patients in the USA.

Finally, we should note the implications for the diagnosis of 'COPD'. Elsewhere, we have discussed the folly of diagnosing a disease using a spirometric ratio. ${ }^{15}$ These survivors of $\mathrm{pBO}$ may never have smoked cigarettes, never have had eosinophilic airway inflammation and had a uniquely deteriorating spirometric growth trajectory. Their $\mathrm{FEV}_{1}$ to FVC ratio will be well below $70 \%$ and well below two z-scores below the mean. Is this 'COPD' to be treated in the same way as someone with an 80 pack-year history? Or a non-smoking woman exposed to biomass fuel? Or a survivor of premature birth, a condition in which there is evidence of oxidative stress $^{16}$ but no inflammation ${ }^{17} 18$ Diagnosing a disease from a physiological ratio is as sensible (and sensitive) as making a specific diagnosis from a creatine or haemoglobin level. Adult physicians need to be challenged to raise their diagnostic and therapeutic game by these survivors of severe childhood airways diseases.

\section{Funding None.}

Competing interests None.

Provenance and peer review Not commissioned; internally peer reviewed.

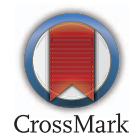

To cite Cullinan P, Bush A. Thorax 2015;70:103104.

Published Online First 20 November 2014

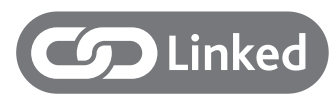

- http://dx.doi.org/10.1136/thoraxjnl-2014-205328

Thorax 2015;70:103-104.

doi:10.1136/thoraxjnl-2014-206168

\section{REFERENCES}

1 Jensen SP, Lynch DA, Brown KK, et al. High-resolution CT features of severe asthma and bronchiolitis obliterans. Clin Radiol 2002;57:1078-85.

2 Murtagh P, Giubergia V, Viale D, et al. Lower respiratory infections by adenovirus in children. Clinical features and risk factors for bronchiolitis obliterans and mortality. Pediatr Pulmonol 2009:44:450-6.

3 Castro-Rodriguez JA, Daszenies C, Garcia M, et al. Adenovirus pneumonia in infants and factors for developing bronchiolitis obliterans: a 5-year follow-up. Pediatr Pulmonol 2006;41:947-53.

4 Colom AJ, Teper AM, Vollmer WM, et al. Risk factors for the development of bronchiolitis obliterans in children with bronchiolitis. Thorax 2006:61:503-6.

5 Larranaga C, Kajon A, Villagra E, et al. Adenovirus surveillance on children hospitalized for acute lower respiratory infections in Chile (1988-1996). J Med Virol 2000;60:342-6.

6 Kajon AE, Mistchenko AS, Videla C, et al. Molecular epidemiology of adenovirus acute lower respiratory infections of children in the south cone of South America (1991-1994). J Med Virol 1996:48:151-6.

7 Fischer GB, Sarria EE, Mattiello R, et al. Post infectious bronchiolitis obliterans in children. Paediatr Respir Rev 2010;11:233-9.

8 Milner $A D$, Murray M. Acute bronchiolitis in infancy: treatment and prognosis. Thorax 1989;44:1-5.

9 Colom AJ, Maffey A, Bournisson FG, et al. Pulmonary function of a paediatric cohort of patients with postinfectious bronchiolitis obliterans. A long term follow-up. Thorax 2015;70:169-74.

10 Tai A, Tran H, Roberts M, et al. The association between childhood asthma and adult chronic obstructive pulmonary disease. Thorax 2014; 69:805-10.

11 Tai A, Tran H, Roberts M, et al. Outcomes of childhood asthma to the age of 50 years. J Allergy Clin Immunol 2014;133:1572-8.

12 Hyde DM, Blozis SA, Avdalovic MV, et al. Alveoli increase in number but not size from birth to adulthood in rhesus monkeys. Am J Physiol Lung Cell Mol Physiol 2007;293:L570-9.

13 Narayanan M, Beardsmore CS, Owers-Bradley J, et al. Catch-up alveolarization in ex-preterm children: evidence from (3)He magnetic resonance. Am J Respir Crit Care Med 2013;187:1104-9.

14 Narayanan M, Owers-Bradley J, Beardsmore CS, et al. Alveolarization continues during childhood and adolescence: new evidence from helium-3 magnetic resonance. Am J Respir Crit Care Med 2012;185:186-91.

15 Postma DS, Brusselle G, Bush A, et al. I have taken my umbrella, so of course it does not rain. Thorax 2012;67:88-9.

16 Filippone M, Bonetto G, Corradi M, et al. Evidence of unexpected oxidative stress in airways of adolescents born very pre-term. Eur Respir $J$ 2012;40:1253-9.

17 Baraldi E, Bonetto G, Zacchello F, et al. Low exhaled nitric oxide in school-age children with bronchopulmonary dysplasia and airflow limitation. Am J Respir Crit Care Med 2005;171:68-72.

18 Carraro S, Piacentini G, Lusiani M, et al. Exhaled air temperature in children with bronchopulmonary dysplasia. Pediatr Pulmonol 2010;45:1240-5. 